\title{
El derecho al pago anticipado de los consumidores y los créditos hipotecarios otorgados con subsidio del Estado
}

\author{
Magda Eveling Roa Quispe / José Luis Herrera Pachari \\ Instituto Nacional de Defensa de la Competencia y de la Protección \\ de la Propiedad Intelectual, Lima, Perú
}

Recibido: 1/9/2017 / Aprobado: 17/2/2019

doi: 10.26439/iusetpraxis2018.n48-49.4501

\begin{abstract}
REsumen. En este artículo, se analiza el derecho de todo consumidor a realizar pagos anticipados en las operaciones activas de crédito y su relación con las políticas impulsadas por el Estado para lograr el acceso a la vivienda de los sectores sociales con menores recursos económicos. El Estado, mediante el Fondo Mivivienda S. A., otorga subsidios para el financiamiento de la adquisición de bienes inmuebles a través de créditos hipotecarios brindados por las entidades del sistema financiero. En este caso, en los pronunciamientos emitidos por los órganos la realización de prepagos no constituye una vulneración al derecho de los consumidores.
\end{abstract}

PALABRAS CLAVE: derecho del consumidor / pago anticipado / crédito hipotecario Mivivienda / Bono del Buen Pagador / Premio al Buen Pagador / acceso a la vivienda / política pública

\section{Consumer's right to advance payment and mortgage loans granted with government subsidy}

Abstract: This article analyzes the right of every consumer to make advance loan payments and its relationship with the policies promoted by the government for low-income social groups to gain access to housing. Through Fondo Mivivienda S. A., the government grants people subsidies to obtain real estate using mortgage loans provided by financial institutions. In this case, according to Indecopi's decision-making bodies, losing the subsidies for making advance payments is not a violation of the consumer's right.

KEYWORDS: consumer's right / advance payment / Mivivienda mortgage loan

/ Good Payer's Bonus / Good Payer's Prize / access to housing / public policy 


\section{INTRODUCCIÓN}

El pago anticipado en las operaciones de crédito estuvo en debate a lo largo de los últimos años. Inicialmente, se estableció la prohibición de su inclusión en los contratos de operaciones activas; luego se incluyó en los contratos, pero con la consecuencia inmediata del pago de una penalidad, para, finalmente, reconocerlo como un derecho del consumidor.

El reconocimiento del derecho al pago anticipado, en los últimos años, ha incorporado a su definición contenidos subyacentes, tales como (i) la prohibición de la restricción o impedimento material para el ejercicio, (ii) el establecimiento de horarios o fechas específicas para su realización sin justificación, así como (iii) la fijación de determinadas agencias o zonas geográficas para su ejercicio por parte de las entidades financieras. Ello ha contribuido a que las entidades financieras incluyan dentro de sus variables y factores de medición de riesgo crediticio la posibilidad de que los consumidores efectúen pagos anticipados. Asimismo, coadyuva a la transparencia ${ }^{1}$ y la competencia entre las empresas en el mercado financiero.

Adicionalmente, el Estado impulsó acciones de política pública ${ }^{2}$ a través de las cuales buscó fomentar el acceso de la población con menores recursos a una vivienda familiar. De esta manera, atiende a la brecha significativa entre la oferta (número de proyectos inmobiliarios destinados para vivienda) y la demanda (número de familias que pueden financiar la compra de una vivienda) en el sector inmobiliario. Para Bourdieu (2002): "El Estado contribuye vigorosamente a producir el estado del mercado de la vivienda a través de inversiones financieras y la doble construcción de la demanda y de la oferta, por medio de recursos, leyes, reglamentos y crédito a los constructores" (p. 32). En concordancia con lo citado, las políticas públicas que se impulsan desde el Estado no solamente ayudan a la generación de la demanda, sino a la

1 Entendemos como transparencia, siguiendo a Molina Ávila (2013, p. 540), a aquellas políticas y normas que tienen por finalidad lograr que los clientes de las entidades de crédito consigan comprender sin dudas ni ambigüedades el alcance de sus derechos y obligaciones. Alcanzar este objetivo de claridad informativa o transparencia resulta trascendental en este ámbito, en el que la especialidad y complejidad de los términos y condiciones de los contratos los hace frecuentemente de difícil comprensión para el cliente que carezca de conocimientos financieros.

2 Acciones del Estado que nacen para atender de manera efectiva problemas de interés público. 
consolidación de la oferta, y con ello también a la dinamización y competitividad del mercado inmobiliario.

En efecto, por el lado de la demanda, se entendió que las familias con menores recursos no podían costear el precio de las viviendas que se ofrecían en el mercado, ni acceder al financiamiento de las entidades del sistema financiero o, de obtenerlo, sería a un costo muy elevado (tasa de interés y seguros) por el riesgo que representaban. Por ello, las acciones de política pública impulsadas por el Estado tenían que ir de la mano con la aplicación de subsidios al precio de las viviendas o al crédito hipotecario (como el Premio al Buen Pagador y el Bono del Buen Pagador).

Por el lado de la oferta, en el mercado inmobiliario se amplió el número de proyectos de viviendas disponibles y el número de empresas ofertantes. Se diversificó la cartera de proyectos por área urbana y las inmobiliarias buscaron diferenciarse entre sí. Todo lo anterior, a fin de captar el número creciente de consumidores que buscaban adquirir viviendas a través de un financiamiento con el subsidio del Estado. En el mercado financiero ${ }^{3}$, la posibilidad de que más personas puedan calificar a un crédito hipotecario implicaba una mayor dinamización del sector y la creación de un nuevo producto: el crédito hipotecario Mivivienda.

En suma, la incorporación de la política pública de facilitar la adquisición de una vivienda a través de un subsidio estatal para las familias con menos recursos y el reconocimiento del derecho al pago anticipado de todo consumidor son instituciones que se han consolidado a la par. Actualmente, han confluido y generado un debate sobre sus efectos y la prevalencia de una o de la otra en el ordenamiento jurídico.

¿Qué ha sucedido en la práctica? Algunos consumidores que han obtenido créditos hipotecarios Mivivienda y han cancelado las cuotas mensuales, luego de un determinado período, decidieron efectuar pagos anticipados totales o parciales de su préstamo. Como consecuencia de ello, las entidades del sistema financiero, atendiendo a lo establecido en los contratos suscritos y las normas vigentes, procedieron

3 De ese modo, las entidades financieras se convierten en una de las instituciones más importantes de la sociedad actual, pues en gran parte son los responsables del crecimiento económico, al actuar como mediadoras entre el ahorro y la inversión en una dinámica económica y financiera que indica el potencial de desarrollo de una sociedad (Mishkin, 2014, p. 269). 
a descontar de esos depósitos el importe que corresponde al reembolso total o parcial, ya sea del Premio al Buen Pagador o del Bono del Buen Pagador para el Estado.

En ese sentido, el presente artículo analiza si la conducta de los proveedores constituye una restricción o vulneración al derecho del pago anticipado de los consumidores. Principalmente, atiende a los pronunciamientos emitidos por los órganos resolutivos de Indecopi. Además, expone los fundamentos que sustentan el derecho al pago anticipado, la estructura y el funcionamiento de los créditos hipotecarios canalizados a través del Fondo Mivivienda, así como la naturaleza de los subsidios otorgados por el Estado mediante el Premio al Buen Pagador o el Bono del Buen Pagador.

\section{El DeRecho A EFECTUAR PAgos anticipados DE LOS CONSUMIDORES EN TODA OPERACIÓN DE CRÉDITO}

En el ámbito normativo ${ }^{4}$ y jurisprudencial, se ha reconocido el derecho de los consumidores a que en toda operación de crédito puedan realizar el pago anticipado o prepago de los saldos, en forma total o parcial, con la consiguiente reducción de los intereses compensatorios generados al día de pago y la liquidación de comisiones y gastos. Asimismo, se ha recogido legislativamente que, en el ejercicio del derecho al pago anticipado, no sea aplicable a los consumidores ningún tipo de penalidades bajo cualquier denominación o se efectúen cobros que revistan un origen o efecto similar.

4 Así, el artículo 65 de la Constitución Política del Perú (1993) señala que el Estado defiende el interés de los consumidores y usuarios. Para tal efecto, garantiza el derecho a la información sobre los bienes y servicios que se encuentren a su disposición en el mercado. En atención a dicha disposición, se ha aprobado durante esta última década una serie de normas vinculadas a su desarrollo, siendo una de ellas el reconocimiento al derecho al pago anticipado.

En el ámbito normativo, el artículo 86 de la Ley 29571 (2010), Código de Protección y Defensa del Consumidor, reconoció que los consumidores tienen derecho, en toda operación de crédito a plazos bajo el sistema de cuotas o similares, a efectuar el pago anticipado o prepago de los saldos, en forma total o parcial, con la consiguiente reducción de los intereses compensatorios generados al día de pago y liquidación de comisiones y gastos derivados de las cláusulas contractuales pactadas entre las partes, sin que les sean aplicables penalidades de algún tipo o cobros de naturaleza o efecto similar. 
En consecuencia, en los últimos años, la Sala ha sancionado el cobro indebido de penalidades y comisiones por pago anticipado, al considerarlas como formas de recuperación de los intereses que los proveedores dejarían de percibir:

Esta Sala [...] no puede convalidar la desnaturalización del derecho de los consumidores a realizar pagos anticipados en forma total o parcial reconocido por el literal g) del artículo 5 de la Ley de Protección al Consumidor, el cual no es de libre disposición y regula las relaciones entre los particulares. En tal sentido, el intento del Banco de revertir los efectos del derecho del señor García a efectuar un pago anticipado de su deuda mediante el cobro de una penalidad por cancelación anticipada constituye una vulneración del mencionado derecho. (Resolución 3784-2003/TDC-INDECOPI, 2004)

La defensa de la Caja Cusco frente a tal requerimiento ha consistido en señalar que informó a la Superintendencia de Banca y Seguros su tarifario de comisiones para las operaciones activas; sin embargo, dicha acción no tiene incidencia en el hecho de que no pudo sustentar que el cobro de la comisión respondía a los gastos administrativos derivados de la operación de cancelación anticipada y, por tal razón, se produjo una vulneración al derecho de los consumidores recogido en el artículo 5, literal g), de la Ley de Protección al Consumidor. (2004)

Es más, también se configura su contenido con el establecimiento de restricciones o limitaciones materiales vinculadas a los horarios, lugares y fechas para su ejercicio. Asimismo, en otros casos, la Sala ha sancionado el empleo de mecanismos de obstaculización al ejercicio de este derecho, tales como demoras en el procesamiento del pago anticipado con el objeto de cobrar los intereses devengados en dicho período, entre otras prácticas similares.

Cabe agregar que a lo largo del procedimiento la denunciada, si bien ha señalado que atendió más de dos mil solicitudes de cancelación anticipada, y para ello ha adjuntado una relación detallada de los clientes que así lo solicitaron, no ha aportado medio probatorio alguno que acredite que estas solicitudes fueran atendidas oportunamente y sin contratiempo, así como que los intereses se hayan liquidado en el momento en que se efectuaron los pagos anticipados correspondientes.

Finalmente, es preciso señalar que a diferencia del presente caso, en anteriores procedimientos de oficio, la Sala no ha encontrado responsabilidad en otros proveedores debido a que los mismos se iniciaron en virtud de uno o pocos reclamos; sin embargo, en su desarrollo no existió una labor investigadora suficiente que determine la responsabilidad de 
los proveedores por conductas generalizadas tendientes a infringir las normas de protección al consumidor. Atendiendo a las consideraciones expuestas, corresponde confirmar la resolución apelada que halló responsable a la Caja Nuestra Gente por infracción del artículo 8 de la Ley deProtección al Consumidor.(Resolución 0043-2010/SC2-INDECOPI, 2010)

En el siguiente caso, resulta incuestionable que los montos cobrados por Financiero a sus clientes involucraron el cobro indebido de intereses devengados entre la fecha de solicitud del pago anticipado y la fecha efectiva del pago solicitado, independientemente del criterio que se utilice para determinar la fecha de referencia. Se ha demostrado que esta entidad cobró a sus clientes una liquidación superior a la que correspondía por el devengado de intereses a la fecha de solicitud del pago anticipado; por tanto, corresponde declarar fundada la denuncia en este extremo.

Conforme a lo expuesto, corresponde confirmar la Resolución 015-2008/ INDECOPI-CAJ en el extremo que halló responsable a Financiero por obligar a sus clientes a cancelar los intereses devengados desde la fecha de su solicitud de pago anticipado hasta el pago efectivo de su deuda. (Resolución 1751-2010/SC2-INDECOPI, 2010)

Ahora bien, el derecho de pago anticipado tiene lugar en el marco de las operaciones de crédito (tarjetas de crédito, créditos hipotecarios, crédito de consumo, etcétera). Desde el punto de vista económico, el crédito se entiende como la utilización de fondos de otra persona a cambio de la promesa de devolverlos (normalmente con intereses) en fecha posterior. En realidad, la razón de ser del crédito son precisamente los intereses, es decir, la renta por el uso del dinero prestado, el beneficio económico del prestamista. Sin esta ventaja, el crédito, tal como lo conocemos actualmente, no existiría.

El crédito bancario - entendido como la operación por la cual la entidad financiera, como prestamista, se compromete a entregar al prestatario una suma de dinero u otro elemento representativo de él, recibiendo a cambio, después de un plazo, la devolución del capital, más intereses - reconoce dentro de la actividad múltiples manifestaciones jurídicas, siendo las más representativas el préstamo y la apertura de crédito. (Barbier, 2008, p. 343) 
A través del crédito, el proveedor realiza el cobro de intereses ${ }^{5}$ como retribución por el uso de su capital hasta la cancelación de la obligación, así como el cobro de comisiones y gastos correspondientes a los servicios adicionalmente prestados y costos que genere el crédito durante dicho período.

Acorde con la Resolución SBS 3274-2017, Aprueban Reglamento de Gestión de Conducta de Mercado del Sistema Financiero y modifican el Manual de Contabilidad para las Empresas del Sistema Financiero y el Reglamento de Tarjetas de Crédito y Débito, señala:

Artículo 16.- Comisiones y gastos

Las comisiones y gastos se determinan libremente de conformidad con lo establecido en el artículo 9 de la Ley General:

1. Las comisiones son cargos por servicios adicionales y/o complementarios a las operaciones contratadas por los usuarios, que hayan sido previamente acordados y efectivamente prestados por las empresas.

2. Los gastos son cargos en que incurren las empresas por servicios adicionales y/o complementarios a las operaciones contratadas por los usuarios, que hayan sido previamente acordados y efectivamente prestados por terceros.

5 El interés puede definirse como la contraprestación que corresponde por el uso del dinero en el tiempo. En ese sentido, constituye el precio fundamental de la economía, puesto que estructura el proceso de producción, al coordinar la valoración presente versus la valoración futura de los bienes y servicios.

Los intereses pueden clasificarse atendiendo a diferentes criterios. Entre estos, cabe destacar los dos siguientes: por un lado, si se toma en consideración quién define su tasa, pueden ser convencionales o legales; por otro lado, si se toma en cuenta el tipo de contraprestación que representan, pueden ser compensatorios o moratorios. Tales criterios permiten precisar, a su vez, las siguientes conjugaciones:

(i) Interés convencional compensatorio: es aquel pactado por las partes y compensa el uso del dinero u otra clase de bien.

(ii) Interés convencional moratorio: es fijado por las partes con el objeto de indemnizar la mora en el pago.

(iii) Interés legal compensatorio: lo determina la ley y compensa el uso del dinero u otra clase de bien.

(iv) Interés legal moratorio: también fijado por mandato de la ley con la intención de indemnizar la mora en el pago (ATC 02214-2014-PA/TC, 2014).

Para Fernández Cruz (1991), el interés representa la ganancia o lucro y no una mera retribución o pago compensatorio. De esa forma, sostiene que es posible concebirlo como una prestación accesoria, que represente siempre el rendimiento de esos bienes tomados como capital, independientemente de la finalidad que persigan: lucrativa, a través de la expectativa de ganancia por la aplicación de ese capital; o indemnizatoria, como satisfacción al acreedor de la privación indebida de la posibilidad de aplicación del capital (p. 179). 
Artículo 17. Aplicación de comisiones y gastos

17.1 Las empresas no pueden establecer comisiones o gastos respecto de servicios esenciales y/o inherentes a los productos y/o servicios financieros que hayan sido contratados por el cliente. Se entiende por servicios esenciales y/o inherentes a todas aquellas gestiones o prestaciones que no pueden desvincularse del producto y/o servicio financiero contratado, siendo que su no realización imposibilitaría que las empresas puedan brindarlo u ofrecerlo.

[...]

En tal sentido, el monto total de los mencionados conceptos es programado por el proveedor al inicio del crédito y plasmado en el cronograma de pagos. De ese modo, se proyecta el pago a través del número de cuotas pactadas con el consumidor hasta la amortización total de su deuda.

Siendo así, resulta de especial importancia la capacidad económica ${ }^{6}$ del consumidor para la contratación de este tipo de servicios, pues ello incide directamente en la evaluación del riesgo de la operación y, por consiguiente, en la tasa de interés que aplica el proveedor ${ }^{7}$. Asimismo,

6 Resolución SBS 11356-2008, Reglamento para la Evaluación y Clasificación del Deudor y la Exigencia de Provisiones

Principios generales de la evaluación y clasificación crediticia del deudor

5.1 Criterios de evaluación

El otorgamiento del crédito está determinado por la capacidad de pago del solicitante [las cursivas son mías] que, a su vez, está definida fundamentalmente por su flujo de caja y sus antecedentes crediticios.

La evaluación del solicitante para el otorgamiento del crédito a deudores no minoristas debe considerar, además de los conceptos señalados en el párrafo anterior, su entorno económico, la capacidad de hacer frente a sus obligaciones ante variaciones. Para evaluar el otorgamiento de créditos a deudores minoristas, se analizará la capacidad de pago con base en los ingresos del solicitante, su patrimonio neto, el importe de sus diversas obligaciones y el monto de las cuotas asumidas para con la empresa, así como las clasificaciones crediticias asignadas por las otras empresas del sistema financiero. En el caso de los créditos a pequeñas empresas y a microempresas, las empresas podrán prescindir de algunos de los requisitos documentarios exigidos por esta Superintendencia, pudiéndose elaborar conjuntamente entre cliente y empresa indicadores mínimos, a satisfacción de este organismo de control, que permitan determinar la capacidad de pago para el cumplimiento de la obligación.

Los criterios de evaluación de los deudores que se señalan en el artículo 222 de la Ley General se aplicarán en el contexto de su pertenencia a un grupo económico, conglomerado financiero o mixto, o en base a otros supuestos de riesgo único señalados en el artículo $203[\ldots]$.

7 El interés será mayor con respecto al capital otorgado en razón directa con la duración de la transacción, el riesgo que importa la falta de cumplimiento o retrasos en el pago del mismo, el costo de oportunidad, la cantidad de dinero o bienes y, en algunos casos, las fluctuaciones del valor de estos últimos (Osterling Parodi y Castillo Freyre, 1996, p. 273). 
este factor es determinante para establecer el número de cuotas en que se cancelará la obligación, pues ello dependerá del monto que el consumidor esté dispuesto a asumir, en el período correspondiente para cada una de dichas cuotas.

Sin embargo, no siempre la capacidad económica del consumidor o su disposición a mantener el monto de los conceptos inicialmente pactados con el proveedor perdura en el tiempo. Estos aspectos pueden variar durante el período en que se encuentre vigente el crédito. En consecuencia, en una relación de crédito a plazos, un consumidor que cuente con una mayor liquidez en determinado momento, o que haya contratado la compra de su deuda a través de otro proveedor en términos más convenientes, por ejemplo, puede verse motivado a cancelar un monto mayor al de su cuota próxima a vencer antes del plazo pactado; o, de ser el caso, a cancelar el íntegro de los saldos pendientes de pago frente al proveedor antes de su vencimiento.

Por tanto, considerando que los intereses, comisiones y gastos acordados entre el proveedor y el consumidor son conceptos programados en función del tiempo por el cual se cede el uso del capital destinado al crédito, así como por los servicios propios o de terceros que se prestan durante dicho período, una cancelación efectuada con anterioridad al plazo podría tener como finalidad, por parte del consumidor, la reducción de tales conceptos en el saldo de la deuda que desea cancelar.

El pago anticipado o derecho de prepago implica una cancelación antelada de los créditos obtenidos de forma total o parcial, con la consiguiente reducción de los intereses compensatorios aplicables. Para tales efectos, será necesario que la suma cancelada por el consumidor sea mayor a la que corresponda a la cuota programada, lo cual implicará que tal exceso sea imputado al saldo pendiente de pago de las próximas cuotas aún no devengadas y, por ende, conlleve a la reestructuración del cronograma de pagos previamente pactado, con la consiguiente reducción en el capital adeudado y en los intereses compensatorios subsecuentes, los cuales tendrán que ser recalculados en función de esta modificación en la obligación.

En orden con lo anterior, mediante los pagos anticipados, los consumidores cancelan anteladamente los créditos obtenidos, por lo que, al reducirse el plazo de dicho financiamiento, es pertinente que también se aminore la contraprestación a cargo del consumidor, mediante una reliquidación de los intereses al día de pago. 
Los pagos adelantados, a diferencia de los pagos anticipados, solo constituyen la cancelación de la cuota prevista con anterioridad a su fecha de vencimiento, lo cual no genera una obligación a cargo del proveedor de liquidar nuevamente la deuda y las cuotas programadas. Así pues, en el caso de los pagos adelantados, el consumidor efectúa la cancelación de una cuota días antes de la fecha de vencimiento de la obligación. (Resolución 2633-2010/SC2-INDECOPI, 2010)

En la actualidad, se encuentra vigente la Resolución SBS 3274-2017, Reglamento de Gestión de Conducta de Mercado del Sistema Financiero, que en los numerales 29.1 y 29.2 del artículo 29 señala lo siguiente:

Artículo 29.- Pago anticipado y adelanto de cuotas

29.1 Los usuarios tienen derecho a efectuar pagos por encima de la cuota exigible en el período, considerando para tal efecto lo siguiente:

1. No deben establecerse condiciones o limitaciones para el ejercicio del derecho.

2. No pueden aplicarse comisiones, gastos, penalidades de ningún tipo por el ejercicio del derecho o cobros de naturaleza o efecto similar.

3. Debe informarse, al momento de efectuar la operación, del monto que resulta aplicable por concepto de impuestos.

4. Los usuarios podrán efectuar los pagos en cualquiera de las oficinas de atención al público de la empresa en las que puedan realizarse operaciones de pagos y desembolsos, así como en otros canales adicionales puestos a disposición por la empresa a los usuarios.

29.2 Los pagos efectuados por encima de la cuota exigible en el período, en el caso de créditos bajo el sistema de cuotas, pueden catalogarse como:

1. Pago anticipado. Pago que trae como consecuencia la aplicación del monto al capital del crédito, con la consiguiente reducción de los intereses, las comisiones y los gastos derivados de las cláusulas contractuales al día del pago.

2. Adelanto de cuotas. Pago que trae como consecuencia la aplicación del monto pagado a las cuotas inmediatamente posteriores a la exigible en el período, sin que se produzca una reducción de los intereses, las comisiones y los gastos derivados de las cláusulas contractuales. 
Asimismo, los numerales 29.3 y 29.4 del artículo 29 de la Resolución SBS 3274-2017 precisan lo siguiente:

a) Pagos mayores a las dos (2) cuotas subsiguientes (incluyendo la exigible en el período)

29.3 Los pagos mayores a dos (2) cuotas (que incluye aquella exigible en el período) se consideran pagos anticipados [las cursivas son mías]. En estos casos, las empresas deben requerir a los clientes, al momento de realizar el pago, que señalen si debe procederse a la reducción del monto de las cuotas restantes, pero manteniendo el plazo original, o del número de cuotas con la consecuente reducción del plazo del crédito. La elección debe efectuarse a través de los mecanismos que para tal efecto se establezcan en los contratos y las empresas deben mantener una constancia que permita acreditar la elección realizada. Asimismo, en aquellos casos en los que no se cuente con tal elección, las empresas deben proceder a la reducción del número de cuotas, dentro de los quince (15) días de realizado el pago.

En caso de pago anticipado, las empresas deben entregar, a solicitud de los clientes, los cronogramas de pago modificados, considerando el pago realizado, en un plazo no mayor a siete (7) días de efectuada dicha solicitud. Las empresas deben informar al cliente sobre la posibilidad de solicitar los precitados cronogramas, dejando constancia de esta acción, conforme corresponda al canal de pago empleado. Los clientes pueden manifestar expresamente su voluntad para adelantar el pago de cuotas, procediendo las empresas a aplicar el monto pagado en exceso sobre la cuota del período a las cuotas inmediatas siguientes, conforme lo establece el artículo 29.4.

En cada oportunidad en la cual los clientes expresen su voluntad de efectuar un adelanto de cuotas, sin que se produzca la reducción de intereses, comisiones y gastos derivados de las cláusulas contractuales, y en forma previa a la ejecución del pago, las empresas deben requerir y mantener una constancia que acredite la elección de los clientes de realizar adelanto de cuotas en lugar de un pago anticipado, haciendo referencia en ambos casos de sus implicancias económicas.

b) Pagos menores a las dos (2) cuotas subsiguientes (incluyendo la exigible en el período)

29.4 Los pagos menores o iguales al equivalente de dos (2) cuotas (que incluyen aquella exigible en el período) se consideran adelanto de 
cuotas. En estos casos, las empresas proceden a aplicar el monto pagado en exceso sobre la cuota del período a las cuotas inmediatas siguientes no vencidas [las cursivas son mías].

Los clientes pueden requerir, antes o al momento de efectuarse el pago, que debe procederse a la aplicación del pago como anticipado, resultando aplicable lo indicado en el inciso 29.3.

De ese modo, a partir de las disposiciones mencionadas en el citado reglamento, resulta posible concluir lo siguiente:

(i) Serán considerados como pagos anticipados aquellos pagos mayores a las dos (2) cuotas inmediatas siguientes del crédito (incluyendo la exigible en el período que se realiza el pago). Es decir que el monto deberá aplicarse al capital con la consiguiente reducción de intereses y demás gastos devengados a la fecha de pago.

(ii) Una vez efectuado el pago anticipado, el consumidor deberá indicar si opta por reducir el monto de las cuotas manteniendo el plazo original o, en su defecto, reducir el plazo manteniendo el valor de la cuota. De no indicarlo, la entidad financiera deberá aplicar la reducción del número de cuotas.

(iii) Serán considerados pagos adelantados aquellos pagos menores a las dos (2) cuotas inmediatas siguientes del crédito (incluyendo la exigible en el período que se realiza el pago, siempre y cuando sea exigible). Es decir que el monto deberá aplicarse a las cuotas inmediatamente posteriores a la exigible en el período, sin reducción de intereses y demás gastos devengados a la fecha de pago.

(iv) Aun en el caso de pagos menores a dos (2) cuotas, el consumidor podría instruir a la entidad financiera, antes o al momento del pago, para que este sea considerado como un pago anticipado.

Así pues, entendemos que los diferentes contenidos del derecho al pago anticipado en toda operación de crédito están vinculados, principalmente, a la prohibición de las conductas que conllevan restricciones a la aplicación de sus beneficios, como son la reducción de los intereses, comisiones y gastos, así como la debida imputación en la fecha adecuada y las presunciones recogidas a nivel normativo. Pero, de 
ningún modo, implica la condonación o perdón de la suma capital o importe desembolsado.

\section{FUNCIONAMIENTO Y ESTRUCTURA DE LOS CRÉDITOS HIPOTECARIOS canalizados a través del Fondo Mivivienda S. A. (FMV)}

En atención a una política de acceso a la vivienda y el fomento del ahorro, así como para propiciar la inversión en el sector inmobiliario, en el año 1998, se publicó la Ley 26912, Ley de Promoción del Acceso de la Población a la Propiedad Privada de Vivienda y Fomento del Ahorro mediante Mecanismos de Financiamiento con Participación del Sector Privado, que creó el Fondo Hipotecario de Promoción de la Vivienda (Fondo Mivivienda). A partir del 1 de enero del 2006, en virtud de la Ley 28579, Ley de Conversión del Fondo Hipotecario de la Vivienda (Fondo Mivivienda) a Fondo Mivivienda S. A., la citada entidad se convirtió en Fondo Mivivienda S. A. (FMV).

La Ley 28579 estableció que el FMV tiene la condición de una empresa estatal de derecho privado, comprendida en el ámbito del Fondo Nacional de Financiamiento de la Actividad Empresarial (Fonafe) y adscrita al Ministerio de Vivienda, Construcción y Saneamiento (MVCS), cuyo objeto es la promoción y financiamiento de la adquisición, mejoramiento y construcción de viviendas, especialmente las de interés social ${ }^{8}$. El FMV está facultado para implementar los productos y servicios necesarios para generar oferta y demanda inmobiliaria con fines de vivienda y otorgar

8 Ley 28579, Ley de Conversión del Fondo Hipotecario de la Vivienda (Fondo Mivivienda) a Fondo Mivivienda S. A.

Artículo 1.- Conversión y objeto

Dispónese la conversión del Fondo Hipotecario de Promoción de la Vivienda (Fondo Mivivienda) en una sociedad anónima denominada Fondo Mivivienda S. A. [...]

El Fondo Mivivienda S. A. tendrá por objeto dedicarse a la promoción y financiamiento de la adquisición, mejoramiento y construcción de viviendas, especialmente las de interés social, a la realización de actividades relacionadas con el fomento del flujo de capitales hacia el mercado de financiamiento para vivienda, a la participación en el mercado primario y secundario de créditos hipotecarios, así como a contribuir con el desarrollo del mercado de capitales.

Artículo 2.- Naturaleza jurídica

El Fondo Mivivienda S. A. tendrá la condición de una empresa estatal de derecho privado, de duración indefinida, que se rige por la presente Ley y su Estatuto, encontrándose comprendida bajo el ámbito del Fondo Nacional de Financiamiento de la Actividad Empresarial del Estado (Fonafe) y adscrita al Ministerio de Vivienda, Construcción y Saneamiento. 
financiamiento a las entidades que integran el sistema financiero para incentivar el desarrollo de proyectos habitacionales promovidos $y$ ejecutados por el sector privado, así como el acceso de las personas al crédito hipotecario 9 .

En virtud de su objeto social, el FMV ha diseñado diversos productos con el propósito de facilitar el acceso al crédito hipotecario en condiciones beneficiosas, principalmente, para las personas con menores ingresos económicos. Así, ha desarrolladolos programas Miconstrucción, Mismateriales, Techo Propio, el Nuevo Crédito Mivivienda ${ }^{10}$, entre otros. Entre ellos, el más importante es el crédito hipotecario para adquisición de vivienda, el cual ha tenido diversas denominaciones:

\begin{tabular}{|l|c|c|}
\hline \multicolumn{1}{|c|}{ Tipo de producto } & \multicolumn{2}{c|}{ Vigencia } \\
\hline Crédito Mivivienda Tradicional & Junio de 1998 & Abril del 2006 \\
\hline Crédito Mivivienda Estandarizado & Julio del 2006 & Septiembre del 2009 \\
\hline Nuevo Crédito Mivivienda & Junio del 2009 & Actualidad \\
\hline
\end{tabular}

Fuente: Fondo Mivivienda (2017)

A fin de reducir los riesgos asociados al diseño y promoción del crédito Mivivienda, el FMV celebró con la Corporación Financiera de Desarrollo S. A. (Cofide) un contrato de fideicomiso, mediante el cual le otorgó el dominio fiduciario sobre el patrimonio fideicometido y la consecuente responsabilidad de ejecutar y transferir los recursos del

9 Ley 28579, Ley de Conversión del Fondo Hipotecario de la Vivienda (Fondo Mivivienda) a Fondo Mivivienda S. A.

Artículo 3.- Actividades y funciones

El Fondo Mivivienda S. A. estará facultado a realizar todas las operaciones y ofrecer productos y servicios dentro del marco establecido en su objeto social. Entre sus actividades y funciones principales se encuentran las siguientes:

a) Promover el acceso de la población a la vivienda implementando los productos y servicios necesarios para generar oferta y demanda inmobiliaria con fines de vivienda.

b) Otorgar financiamiento a las entidades que integran el sistema financiero con el objeto de incentivar el desarrollo de proyectos habitacionales promovidos y ejecutados por el sector privado, así como el acceso de las personas al crédito hipotecario.

10 Este producto se encuentra vigente desde junio del 2009 y ha sustituido al producto Crédito Mivivienda Estandarizado, vigente entre julio del 2006 y septiembre del 2009, así como a Crédito Mivivienda Tradicional, vigente entre junio del 1998 y abril del 2006. 
FMV a las instituciones financieras intermediarias (IFI) que colocan los créditos Mivivienda. De esta manera, Cofide es la encargada de transferir a las IFI los recursos del FMV mediante la aprobación de préstamos, que, a su vez, serán canalizados a los usuarios finales - que cumplan con los requisitos correspondientes - a través del otorgamiento de subpréstamos, con la finalidad de destinarlos a la adquisición y construcción de viviendas para casa habitación ${ }^{11}$. El siguiente gráfico permitirá entender a cabalidad el iter contractual descrito:

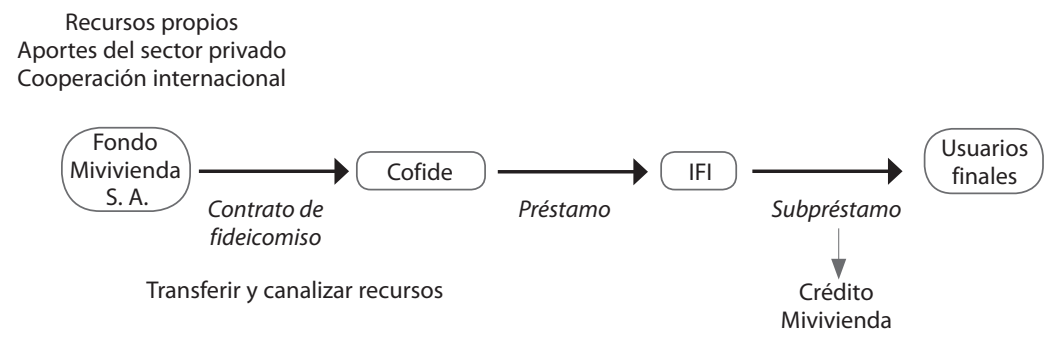

Fuente: Fondo Mivivienda (2017)

Así, por un lado, tenemos una relación entre Cofide y las IFI, que se rige por los términos y condiciones (tasas de interés, comisiones, plazo, moneda de desembolso y pago, plazo de gracia, aplicación de bonos o premios, entre otros) establecidos exclusivamente por el FMV ${ }^{12}$; y, por otro lado, una relación entre las IFI y los usuarios finales, donde el FMV deja a criterio de las IFI la determinación de las tasas de interés y otras condiciones financieras relacionadas con el subpréstamo.

\section{Funcionamiento y aplicación del Premio al Buen Pagador (PBP) EN LOS CRÉditos HiPOTECARIOS MiVIVIENdA}

El Premio al Buen Pagador se creó mediante Decreto de Urgencia 091-2000. Este beneficio nació como un subsidio del $20 \%$ del subpréstamo, destinado a los consumidores que hayan cumplido con el pago puntual de sus obligaciones y de aplicación semestral en forma proporcional.

11 Véase el artículo 4 del Acta de Directorio 03-14D-2013, Reglamento del Crédito Nuevo Crédito Mivivienda.

12 Véase el artículo 7 del Acta de Directorio 03-14D-2013, Reglamento del Crédito Nuevo Crédito Mivivienda. 
Es preciso señalar que tanto el préstamo como el subpréstamo se caracterizan por estar conformados por un tramo no concesional (TNC) $\mathrm{y}$ un tramo concesional (TC). El TNC tiene una periodicidad mensual y equivale a la diferencia entre el importe del subpréstamo y el TC, mientras que este último tiene una periodicidad semestral ${ }^{13}$. Lo expuesto se resume en el siguiente cuadro gráfico:

\begin{tabular}{|c|c|}
\hline \multicolumn{2}{|c|}{ Préstamos y subpréstamos } \\
\hline Tramo no concesional (TNC) & Tramo concesional (TC) \\
\hline $\begin{array}{l}\text { Resultado de restar al } \\
\text { monto desembolsado el } \\
\text { valor del TC }\end{array}$ & - Equivale como máximo a S/ 12 500,00 \\
- Periodicidad mensual & - Tramo en el que resulta aplicable el PBP \\
\hline
\end{tabular}

En otras palabras, el TC de los préstamos y subpréstamos está conformado por las cuotas semestrales que la IFI o el usuario podrá dejar de pagar en el supuesto de que califiquen para el Premio al Buen Pagador (PBP) y siempre que cumplan con los términos y condiciones previstos por el FMV para tal efecto.

Ahora bien, el Premio al Buen Pagador (PBP) consiste, en los términos del reglamento, en la página 109.

Importe al que accede el beneficiario que haya cumplido con cancelar puntualmente las cuotas correspondientes al tramo no concesional. Este premio servirá para cancelar semestralmente el importe del principal e intereses de la cuota a pagarse en dicho período, correspondiente al tramo concesional del subpréstamo. Este premio será de cargo del Fondo.

De ese modo, el Premio al Buen Pagador (PBP) será de cargo del FMV y sirve para cancelar de manera semestral el principal e intereses de la cuota que corresponde por ese período del TC del préstamo otorgado al consumidor. Así, la relación entre el crédito Mivivienda y el Premio al Buen Pagador puede graficarse de la siguiente manera:

13 Véase el artículo 7, inciso g), y el artículo 8, inciso g), del Acta de Directorio 03-14D2013, Reglamento del Crédito Nuevo Crédito Mivivienda. 


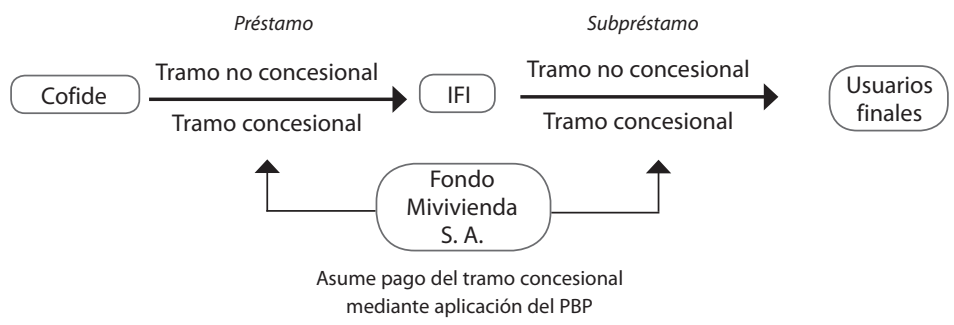

Fuente: Fondo Mivivienda (2017)

A modo de ejemplo, en el supuesto de un súbprestamo por el importe capital de $S / 100$ 000,00 a un plazo de diez (10) años, tendremos que el TNC equivale al importe capital de S/ 87500,00 y el TC a S/ 12 500,00. En condiciones de pago puntual de las cuotas mensuales del TNC (120 cuotas de S/ 729,00, aproximadamente), las cuotas semestrales que le corresponderían cancelar al usuario $(20$ cuotas de $S / 625,00)$ serán asumidas por el FMV. Esto es, al término del crédito, el usuario beneficiado con el PBP solo cancelará el importe capital del TNC (en nuestro ejemplo, S/ 87 500,00) más los intereses acordados.

En este punto, es preciso señalar que el acceso al PBP se evalúa de forma independiente en cada semestre del TC, debido a que su aplicación es progresiva. Así, en caso de que el usuario cancele puntualmente las cuotas del TNC desde el primer mes, al término del semestre solo pagará la cuota mensual correspondiente al TNC, mientras que la cuota semestral del TC está a cargo de los recursos del FMV, en mérito a la puntualidad en sus pagos. Por el contrario, si durante la vigencia del crédito Mivivienda el usuario no cumple con el pago oportuno de una de las cuotas de algún semestre, deberá hacerse cargo tanto de su cuota mensual como de la cuota semestral del TC. En este caso, la cuota semestral será prorrateada en el siguiente semestre en seis (6) armadas mensuales que serán agregadas a las cuotas mensuales del $\mathrm{TNC}^{14}$. Esto significa que, en el escenario de incumplimiento, el usuario debe asumir el pago de ambos tramos del subpréstamo, conforme a lo siguiente:

14 Véase el artículo 8, inciso j), del Acta de Directorio 03-14D-2013, Reglamento del Crédito Nuevo Crédito Mivivienda. 
Subpréstamo
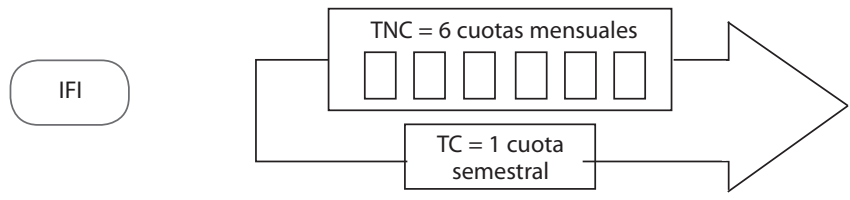

Consecuencias del incumplimiento de pago

El usuario asume el pago de la cuota del TC prorrateada en las seis siguientes cuotas del TNC

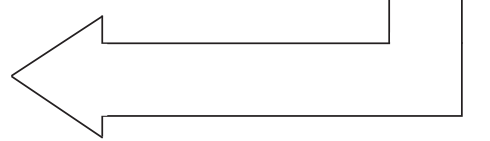

Fuente: Fondo Mivivienda (2017)

Sin perjuicio de lo expuesto, si el usuario cumple con el pago oportuno de las seis cuotas antes citadas, podrá ser calificado nuevamente como "buen pagador" y podrá acceder al PBP en el siguiente semestre ${ }^{15}$.

Las relaciones originadas por el préstamo, así como por el subpréstamo, se rigen, principalmente, por las disposiciones del reglamento ${ }^{16}$ que se encuentre vigente al momento de su celebración.

\section{Naturaleza y funcionamiento del Bono del Buen Pagador (B B P) EN LOS CRÉDITOS HIPOTECARIOS MIVIVIENDA}

Mediante la Ley 29033, Ley de Creación del Bono del Buen Pagador, se instauró el Bono del Buen Pagador (BBP), en el marco de las acciones de la política de acceso de la población a la vivienda, con el objetivo de incentivar y promover el cumplimiento oportuno de los pagos mensuales del

15 Acta de Directorio 03-14D-2013, Reglamento del Crédito Nuevo Crédito Mivivienda Artículo 8.- Términos y condiciones de los subpréstamos

$[\ldots]$

Para efectos de acceder nuevamente al Premio al Buen Pagador en el semestre siguiente, el beneficiario deberá cancelar las cuotas correspondientes a ambos tramos del préstamo, dentro de las condiciones establecidas para ser calificado como "buen pagador". Corresponde a cada IFI, dentro de sus políticas internas, fijar los intereses, gastos $u$ otros conceptos que se cobren, en caso de que el beneficiario no cancele puntualmente la cuota prorrateada del tramo concesional.

16 Véase el artículo 2, inciso j), del Acta de Directorio 03-14D-2013, Reglamento del Crédito Nuevo Crédito Mivivienda. 
crédito Mivivienda ${ }^{17}$. El Bono del Buen Pagador (BBP) consiste en una ayuda económica directa no reembolsable que el Estado otorga a las personas que hayan cumplido con cancelar oportunamente las cuotas correspondientes del crédito Mivivienda, de acuerdo con las condiciones establecidas por el FMV a través de las $\mathrm{IFI}^{18}$. Al ser un subsidio estatal para la adquisición de créditos hipotecarios de interés social, el acceso al Bono del Buen Pagador (BBP) se encuentra sujeto al cumplimiento del marco normativo establecido por el FMV (condiciones, oportunidad y procedimiento de aplicación o inaplicación); sin perjuicio de que cada IFI será responsable de la información que proporciona al respecto, así como de la idoneidad empleada para dar cumplimiento al referido marco normativo.

En términos operativos, el Bono del Buen Pagador (BBP) consiste en la exoneración de pago de las cuotas semestrales (principal e intereses) correspondientes al TC, que serán asumidas por el FMV, siempre que el usuario cumpla con las condiciones establecidas para el pago correspondiente al TNC del subpréstamo. Esto es, el Bono del Buen Pagador (BBP) funciona operativamente de manera igual que el Premio al Buen Pagador (PBP). El funcionamiento operativo del Bono del Buen Pagador (BBP), en el supuesto de cumplimiento de pago de las cuotas del crédito Mivivienda, se explica a continuación:

17 Ley 29033, Ley de Creación del Bono del Buen Pagador, publicada el 7 de junio del 2007 Artículo 1.- Creación

Créase el Bono del Buen Pagador (BBP) como una de las acciones de política de acceso de la población a la vivienda, con el objetivo de incentivar y promover el cumplimiento oportuno de los pagos mensuales del crédito Mivivienda otorgado en nuevos soles.

18 Ley 29033, Ley de Creación del Bono del Buen Pagador, publicada el 7 de junio del 2007 Artículo 1.- Creación

$[\ldots]$

El BBP consiste en la ayuda económica directa no reembolsable por un monto máximo de diez mil nuevos soles (S/ 10 000) que se otorga a las personas que hayan cumplido con cancelar oportunamente las cuotas correspondientes del crédito Mivivienda, de acuerdo con las condiciones determinadas por el Fondo Mivivienda S.A., por medio de las empresas del sistema financiero. 


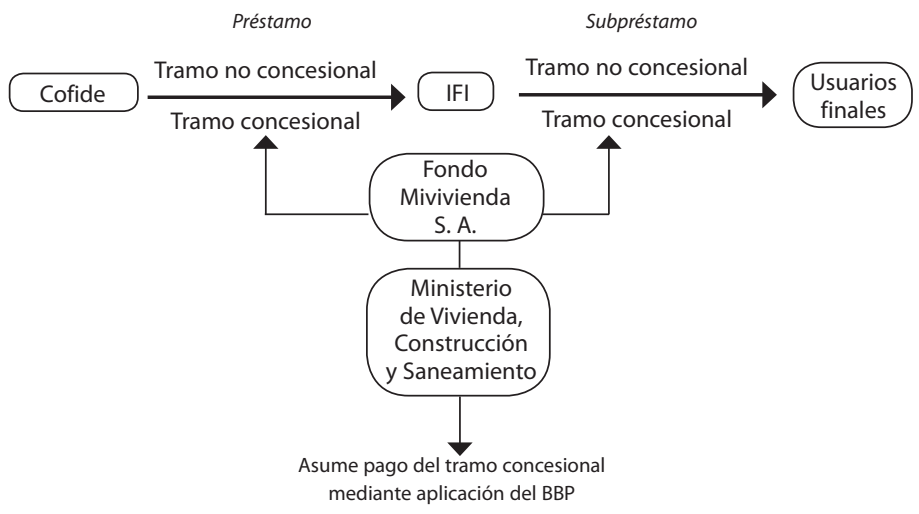

Fuente: Fondo Mivivienda (2017)

En efecto, tal como se advierte en el diagrama anterior, el BBP es otorgado por el Estado y canalizado a través del MVCS. De la misma forma que el PBP, es imputado de manera semestral a favor del consumidor, de conformidad con el Reglamento del Bono del Buen Pagador que se encuentre vigente al momento de la contratación del crédito y de su aplicación.

\section{Aplicación del Premio al Buen Pagador y el Bono del Buen Pagador en los Supuestos de Pago anticipado}

Desde la creación del FMV, tanto este como el MVCS han emitido diversas normas vinculadas al funcionamiento del programa, así como los efectos del PBP y BBP ante la realización de pagos anticipados, las cuales se resumen en el gráfico de la página 109.

Así, el FMV, mediante actas de directorio, emitió diversos Reglamentos de Crédito Mivivienda (tradicional y estandarizado), a través de los cuales reconoció, en un primer momento, la posibilidad de efectuar prepagos sin perder del PBP, luego de transcurridos los primeros diez (10) años de desembolsado el crédito ${ }^{19}$. Sin embargo, a partir del 17 de junio

19 Acta de Directorio, Reglamento de Crédito del Fondo Mivivienda S. A., aprobada el 17 de febrero del 2006

$[\ldots]$

Artículo 21.- Condiciones adicionales de los subpréstamos

$[\ldots]$ 


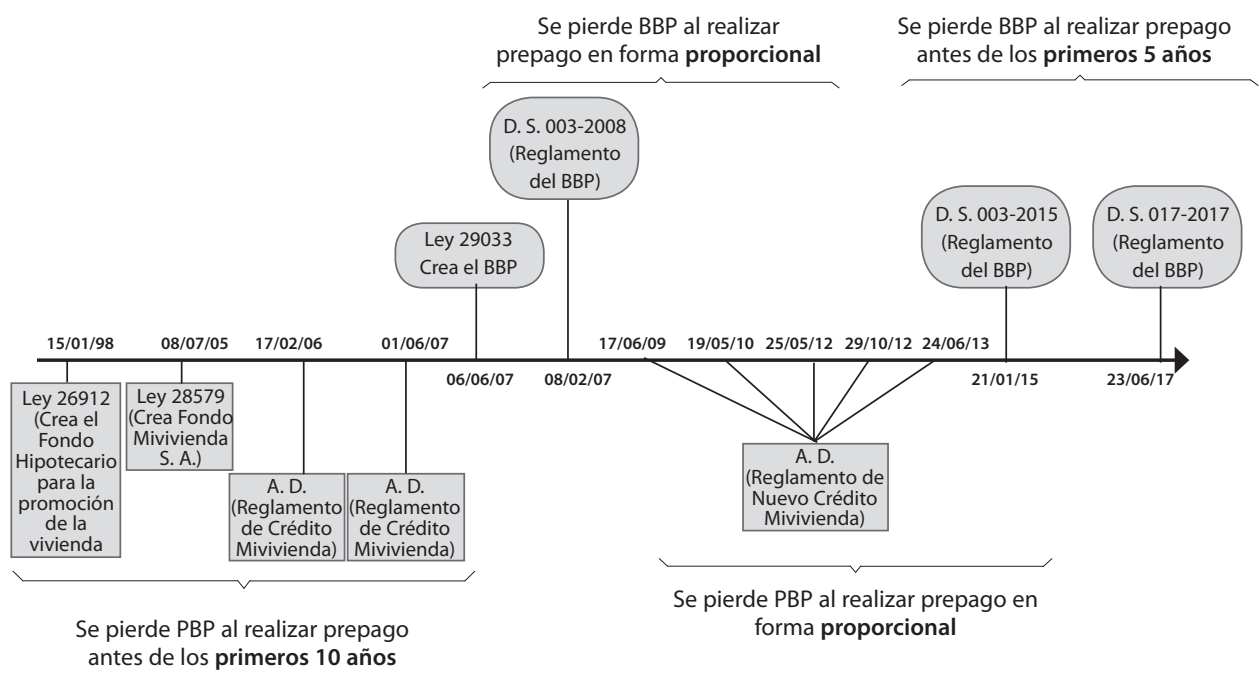

Fuente: Fondo Mivivienda (2017)

del 2009, con la aprobación del primer Reglamento del Nuevo Crédito Mivivienda, precisó que, ante la realización de pagos anticipados, el consumidor perdía el $\mathrm{PBP}^{20}$.

Por otro lado, con la dación de la ley que creó el BBP, el MVCS emitió diversos decretos supremos que, en un primer momento y en la misma línea que el FMV, establecieron que el consumidor perdía el BBP por la

f. Los beneficiarios que realicen prepagos parciales o totales con posterioridad al año diez (10) del subpréstamo accederán al Premio al Buen Pagador en la parte proporcional que corresponda por dicho prepago [las cursivas son mías]. En este caso, el premio se determinará aplicando el $20 \%$ sobre el importe del principal prepagado. En el caso de prepagos totales, el importe a prepagar será el saldo del tramo no concesional, aplicándose como premio el saldo del tramo concesional [las cursivas son mías]. No será de aplicación el Premio al Buen Pagador a aquellos prepagos que se realicen antes del plazo indicado

20 Acta de Directorio 01-17D-2009, Reglamento del Crédito Nuevo Crédito Mivivienda, aprobada el 17 de junio del 2009

$[\cdots]$

Artículo 7.- Términos y condiciones de los subpréstamos

$[\ldots]$

k. Los beneficiarios que realicen prepagos parciales o totales en cualquier momento durante la vida del subpréstamo perderán el Premio al Buen Pagador en la parte proporcional que tenía el tramo concesional al momento del desembolso [las cursivas son mías]. 
realización de prepagos ${ }^{21}$. Esta situación cambió con la emisión del Decreto Supremo 003-2015-VIVIENDA del 21 de enero del 2015, a través del cual se estableció que dicho beneficio no se perdía en caso de que se realice un prepago luego de transcurridos los primeros cinco (5) años ${ }^{22}$.

En ese contexto, la pérdida del Premio (en cualquier momento del crédito hipotecario) o del Bono (antes de los primeros cinco años) no constituye una restricción que impida la realización de pagos anticipados y, por ende, el derecho de los consumidores. Por el contrario, debido al cambio de la situación financiera del consumidor, es el restablecimiento de las condiciones en las cuales se hubiera otorgado un crédito hipotecario sin ayuda o intervención del Estado.

Sin perjuicio de lo mencionado, la Comisión de Protección al Consumidor 1 también ha considerado supuestos en los cuales al consumidor no le correspondía perder los beneficios otorgados:

Resolución Final 2127-2017/CC1: La Comisión determinó que el proveedor denunciado excluyó al consumidor del beneficio del Bono del Buen Pagador de su CRÉDITO Hipotecario MiVivienda Más, a pesar de haber cumplido con los requisitos para su otorgamiento. Esto es, el pago anticipado fue realizado luego de cumplido los cinco (5) primeros años luego de desembolsado el crédito hipotecario.

La citada Resolución Final desarrolló los supuestos de aplicación diferenciada entre el Bono del Buen Pagador y el Premio al Buen Pagador, estableciéndose que cada uno obedecía a una naturaleza distinta y, por ende, tenían regímenes especiales de aplicación para cada crédito hipotecario Mivivienda.

21 Decreto supremo 003-2008-VIVIENDA, Reglamento de la Ley de Creación del Bono del Buen Pagador, publicado el 8 de febrero del 2008

$[\ldots]$

Artículo 7.- Causales de reembolso del BBP

Los beneficiarios deberán reembolsar el BBP cuando:

$[\ldots]$

7.2 Prepaguen en forma parcial o total el crédito MIVIVIENDA en virtud del cual se le asignó el BBP, según lo establecido por el FMV [las cursivas son mías].

22 Decreto Supremo 003-2015-VIVIENDA, Reglamento de la Ley de Creación del Bono del Buen Pagador, publicado el 21 de enero del 2015

[...]

Artículo 6.- Causales de reembolso del BBP

Los beneficiarios deben reembolsar el BBP cuando:

$[\ldots]$

6.2 Prepaguen en forma total el crédito MIVIVIENDA, en virtud del cual se le asignó el BBP, antes de los cinco (05) años de su desembolso por parte de la IFI, según lo establecido por el FMV [las cursivas son mías]. 
Por ello, resultaba importante establecer (i) en qué momento se contrataba el producto financiero, así como (ii) la fecha en que se realizaba el pago anticipado total o parcial, para determinar la aplicación o no del beneficio, según sea el caso, y su correlación con el marco normativo aplicable.

Resolución Final 0582-2018/CC1: Los denunciantes cuestionaron al banco por no haber considerado el Premio al Buen Pagador (tramo concesional), al momento en que realizaron el pago anticipado de su Crédito Hipotecario Mivivienda, a través del desembolso del $25 \%$ de sus aportes a su fondo de pensiones.

La Comisión estableció que la entidad financiera no efectuó adecuadamente la cancelación de su crédito hipotecario Mivivienda a nombre de los denunciantes, con la aplicación del $25 \%$ de los aportes de sus fondos de pensiones de la AFP. La decisión determinó que, en primer lugar, los desembolsos realizados con ocasión de la entrada en vigencia de la Ley 30478 debían ser considerados como pagos anticipados; para ello, se debía tener en cuenta el procedimiento operativo de la SBS. En segundo lugar, en el caso de créditos hipotecarios Mivivienda que cuenten con el Premio al Buen Pagador, correspondía que el beneficio por el prepago sea imputado íntegramente al tramo no concesional, quedando incólume el tramo concesional del préstamo.

Resolución Final 0473-2018/CC1: El denunciante cuestionó que la entidad financiera no cumplió con tramitar el desembolso del $25 \%$ de la CIC de su fondo de pensiones de AFP para amortizarlo como pago anticipado a su crédito hipotecario Mivivienda, el cual fue obtenido para la adquisición de un departamento, el mismo que ha sido su primera vivienda; bajo el argumento de que tenía inscrito a su nombre otro bien inmueble de mayor antigüedad, el mismo que tendría las características de un depósito.

La Comisión consideró que el proveedor denunciado no cumplió con tramitar el desembolso del $25 \%$ del fondo de pensiones del consumidor para que amortice su crédito hipotecario. Para ello, desarrolló los alcances de la definición de primera vivienda y primer inmueble, establecida en la Ley 30478 y en la legislación en general, que determina que debe entenderse aquella como la adquisición de un bien inmueble o ambiente destinado o que tenga la posibilidad de ser destinado para su uso como residencia de una familia. 
De ese modo, el departamento y los depósitos, al momento de su adquisición, formaban parte de una misma unidad inmobiliaria, no pudiendo considerarse a los depósitos como una vivienda de manera independiente, conforme a las disposiciones legales, sino que su utilización sería complementaria a un departamento en un edificio multifamiliar.

Es más, el consumidor para obtener legalmente el desembolso del crédito hipotecario Mivivienda, no ha tenido que poseer una vivienda a título de propiedad. Esto es, la adquisición del departamento fue su primera vivienda; por ende, el financiamiento estaba dirigido para lograr dicha finalidad, más aún si la propia denunciada en el contrato de préstamo Mivivienda señaló que el cliente había superado la evaluación y calificación correspondiente. (Comisión de Protección al Consumidor 1, 2017)

Así, la jurisprudencia de los órganos resolutivos de Indecopi, a través de la Resolución Final 284-2015/CC1 y la Resolución 1123-2016/ SPC-INDECOPI, ha señalado que el PBP, al tratarse de una ayuda económica, no puede ser considerado como una penalidad o restricción al derecho de pago anticipado de todo consumidor, pues el importe depositado por el deudor se imputará completamente al capital del tramo concesional como no concesional, integrantes ambos del monto total desembolsado en una condición normal. Finalmente, en términos prácticos, ante la realización de un pago anticipado, el consumidor deberá cancelar el valor real del importe desembolsado para la adquisición del bien inmueble, al igual que cualquier otro consumidor que hubiera obtenido un crédito hipotecario por su propia cuenta.

\section{CONCLusiones}

El contenido del derecho al pago anticipado en toda operación de crédito por parte de los consumidores está vinculado, principalmente, a la prohibición de conductas de las entidades financieras que conlleven restricciones, por cualquier motivo, para la aplicación de sus beneficios intrínsecos, como la reducción de los intereses, comisiones y gastos, la debida imputación en la fecha adecuada y la falta de aplicación de las presunciones recogidas en el ámbito normativo que lo diferencian del pago adelantado. Pero de ninguna manera implica la condonación o perdón de la suma capital o importe desembolsado; es más, se entiende que el pago anticipado debe dirigirse únicamente al capital. 
El Premio al Buen Pagador y el Bono del Buen Pagador son beneficios distintos, cuya naturaleza está constituida como un subsidio otorgado por el Estado y con operatividad similar, que busca cubrir un determinado importe que dejará de pagar el consumidor, como consecuencia de haber cancelado oportunamente las cuotas del crédito hipotecario Mivivienda.

El Premio al Buen Pagador y el Bono del Buen Pagador no se otorgan de manera simultánea o conjunta. Su aplicación está vinculada al valor del bien inmueble adquirido por el consumidor a través del financiamiento del FMV; las condiciones contractuales asumidas y determinadas por la IFI, en cada caso concreto, definen cuál de ellos es aplicable para cada usuario. Al respecto, podemos rescatar las principales diferencias entre ambos beneficios:

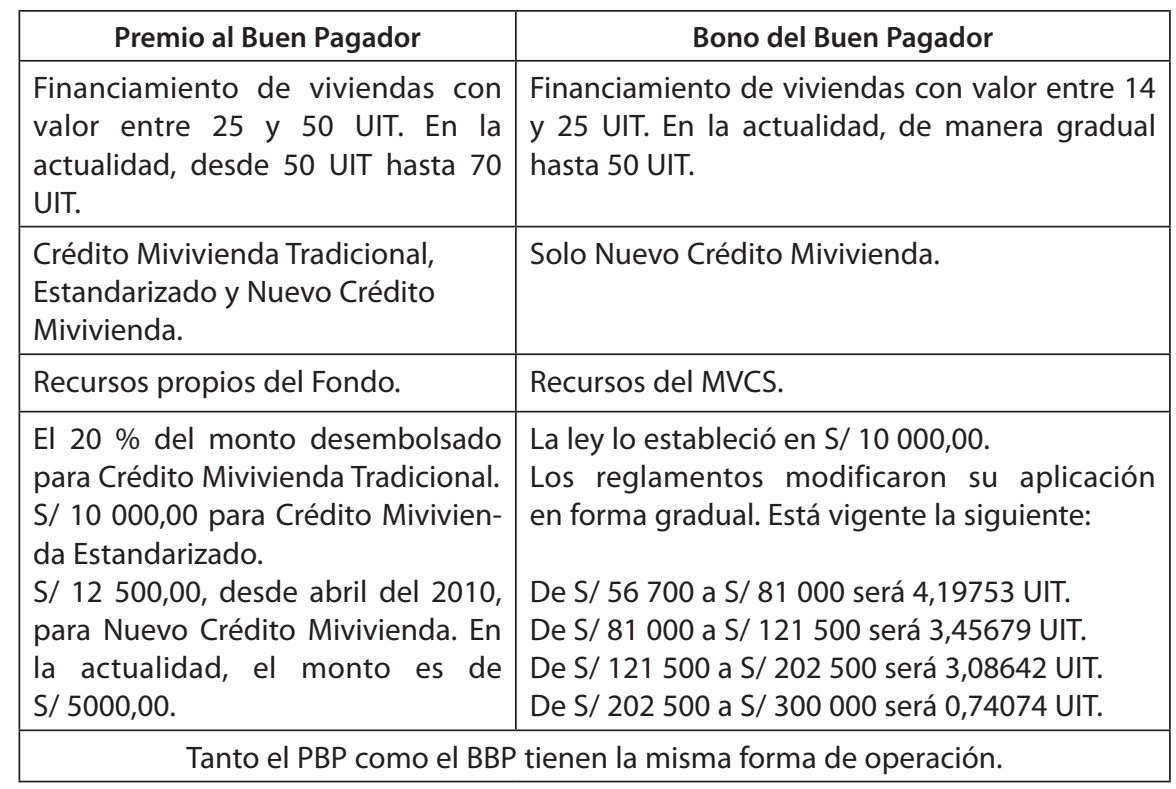

El marco normativo para el Premio al Buen Pagador establece que, ante la realización de un pago anticipado, dicho importe debe ser imputado a ambos tramos del subpréstamo (crédito hipotecario Mivivienda) de forma proporcional al porcentaje que cada tramo representa respecto del monto desembolsado. Esto es, la inaplicación del Premio al Buen Pagador será proporcional al monto que representa el TC respecto del 
subpréstamo. Acorde con el artículo 8, inciso k), del Acta de Directorio 03-14D-2013, Reglamento del Crédito Nuevo Crédito Mivivienda, establece que se podrá efectuar el prepago parcial o total del subpréstamo. El importe del prepago del subpréstamo deberá ser utilizado por la IFI para efectuar el prepago del préstamo a favor de Cofide, en representación del Fondo, para lo cual tiene un plazo de hasta 20 días calendario contados a partir de la fecha en que se efectuó la precancelación.

Asimismo, la realización del prepago del subpréstamo exige que dicho importe sea utilizado por la IFI para efectuar el prepago del préstamo. De conformidad con el artículo 8 del Acta de Directorio 03-14D-2013, Reglamento del Crédito Nuevo Crédito Mivivienda, se establece que se podrá efectuar el prepago parcial o total del subpréstamo. El importe del prepago del subpréstamo deberá ser utilizado por la IFI para efectuar el prepago del préstamo a favor de Cofide en representación del FMV, para lo cual tiene un plazo de hasta 20 días calendario contados a partir de la fecha en que se efectuó la precancelación.

Este criterio ha sido desarrollado ampliamente por la jurisprudencia de Indecopi a través de la Resolución Final 284-2015/CC1 y la Resolución 1123-2016/SPC-INDECOPI. La IFI se encuentra obligada a cumplir con las condiciones fijadas por el FMV para el otorgamiento del crédito Mivivienda y el acceso tanto al Premio al Buen Pagador como al Bono del Buen Pagador, según corresponda, teniendo en cuenta a su vez la normativa emitida para cada caso. Es decir, corresponde al FMV emitir el marco legal que sustente la operatividad de este producto financiero.

Así, la pérdida del Premio o del Bono no es una restricción sin justificación que impida la realización de pagos anticipados. Se trata del restablecimiento de las condiciones en las cuales se hubiera otorgado un crédito hipotecario sin ayuda o intervención del Estado, debido al cambio de la situación financiera del consumidor. En términos prácticos, significa únicamente que el consumidor deberá pagar el valor real del importe desembolsado para la adquisición del bien inmueble, al igual que cualquier otro consumidor que hubiera obtenido un crédito hipotecario por su propia cuenta. 


\section{REFERENCIAS}

Barbier, E. A. (2008). Contratación bancaria (3. ${ }^{\mathrm{a}}$ ed., vol. I). Buenos Aires: Astrea.

Bourdieu, P. (2002). Las estructuras sociales de la economía. Buenos Aires: Manantial.

Fernández Cruz, G. (1991). La naturaleza jurídica de los intereses: punto de conexión entre derecho y economía. Derecho PUCP, 45, 177-213.

Mishkin, F. (2014). Moneda, banca y mercados financieros (10. a ed.). México D. F.: Pearson Educación.

Molina Ávila, M. (2013). Contratación bancaria. En P. Fernández Burgueño, M. Molina Ávila y A. Porto Cortés (Eds.), Manual de derecho de consumo (1. a ed., pp. 511-545). Madrid: Lex Nova.

Osterling Parodi, F., y Castillo Freyre, M. (1996). Tratado de las obligaciones (vol. V). Lima: Pontificia Universidad Católica del Perú, Fondo Editorial.

Proceso de Amparo 02214-2014-PA/TC. (2014). Tribunal Constitucional. Recuperado del sitio de internet del Tribunal Constitucional: http://www.tc.gob.pe/jurisprudencia/2015/02214-2014-AA\%20 Resolucion.pdf

Resolución 0043-2010/SC2-INDECOPI. (2010). Sala de Defensa del Consumidor.

Resolución 1751-2010/SC2-INDECOPI. (2010). Sala de Defensa del Consumidor 2.

Resolución 1850-2010/SC2-INDECOPI. (2010). Sala de Defensa de la Competencia 2.

Resolución 3784-2003/TDC-INDECOPI. (2004). Tribunal de Defensa del Consumidor de Indecopi. 
